\title{
Psychosomatic symptoms of the Couvade syndrome in Finnish and Polish expectant fathers
}

\author{
Urszula Sioma Markowska ${ }^{1}$, Michalina Zyg ${ }^{2}$, Bogumiła Kiełbratowska ${ }^{3}$ \\ ${ }^{1}$ Department of Nursing in Gynecology and Obstetrics, Woman's Health Division, \\ School of Health Sciences in Katowice, Medical University of Silesia, Katowice, Poland \\ ${ }^{2}$ Voivodeship Specialist Hospital Megrez Sp.z o.o., \\ Gynecological and Maternity Ward with the Oncological Gynecology Subunit, Tychy, Poland \\ ${ }^{3}$ Department of Obstetrics, Medical University of Gdansk, Poland
}

\begin{abstract}
Objectives: The aim of the study was to assess the occurrence of symptoms associated with the Couvade syndrome in two groups of men of Polish and Finnish nationality, and to perform a comparative analysis.

Material and methods: The study was conducted in two groups of men (expectant fathers): 51 Poles and 40 Finns using a self-constructed questionnaire prepared in Polish and English languages. The statistical analysis was performed in Microsoft Office Excel 2010 and Statistica 12. The Pearson's test was calculated, and the statistical significance level was $p<0.05$.

Results: The most common physical symptoms reported by the Polish men were weight gain (78\%) and gastric disorders $(80 \%)$, whereas the Finns most frequently declared weight gain (60\%). As for emotional symptoms, mood swings $(p=0.0001)$ and sleep disorders $(p=0.00004)$ were significantly more common in the Poles, whilst the Finns experienced frustration $(p=0.0403)$ and nervousness $(p=0.01579)$ significantly more frequently. The Finnish respondents more often used professional forms of preparation for childbirth and parenthood $(p=0.00229)$.

Conclusions: Psychosomatic symptoms of the Couvade syndrome are significantly more common in Polish than in Finnish expectant fathers. Compared with Polish fathers, Finns significantly more frequently attend ante-natal classes. Ante-natal care should encompass education of men as they do experience the symptoms of the Couvade syndrome during their wives'/partners' pregnancies.
\end{abstract}

Key words: pregnancy, couvade, sympathetic pregnancy, psychosomatic symptoms

Ginekologia Polska 2018; 89, 1: 35-39

\section{INTRODUCTION}

The ICD-10 classification from 2010 and the DSM IV classification from 2000 do not mention the Couvade syndrome. However, the Dictionary of Medical Syndromes from 1997 contains a definition according to which this syndrome refers to neurotic disorders that occur in men whose partners are pregnant, usually in the first and third trimesters of pregnancy [1, 2]. Many authors have attempted to develop a definition of the Couvade syndrome [3-5], also known as sympathetic pregnancy or expectant father syndrome. According to Głażewska, the global prevalence of the Couvade syndrome ranges from $11 \%$ to $97 \%$. The fewest symptoms are experienced by men in the United
Kingdom, Sweden and the United States of America, moderate incidence is reported for men from Columbia, Canada and Thailand, while Polish and Chinese men are characterized by the most common occurrence of this syndrome (approximately 70\%) [2]. There are several classifications of typical symptoms of the Couvade syndrome according to different authors. For example, Conner et al. divides the symptoms into three groups: gastrointestinal (weight gain, appetite changes, nausea, bloating, stomach ache), respiratory (respiratory tract infections) or nervous (anxiety, sleep disorders, nervousness) [6], while Brennan enumerates 35 symptoms, of which 8 are psychological and 27 physical [7]. 
A number of authors have emphasized a positive role of emotional support provided by the husband/partner during pregnancy and labor. The engagement of the husband intensifies the relationships with the wife and offers men a chance to fully experience joy related with the future parenthood [2, 8-10].

Raphael-Leff distinguishes between two categories of men: involved fathers who are interested in their partners' pregnancies (eager to take part in childbirth and help in care for the neonate) and fathers-observers who are less engaged in pregnancy and post-partum period [11]. By experiencing symptoms of this syndrome, a husband/partner wishes to publicly confirm his changing status $[2,12]$. Moreover, childhood experiences affect fathers' attachment to their own children. The child mostly identifies him - or herself with the mother, whom he or she considers to be the primary model. Later, the child begins to relate more to the father thanks to whom the child identifies his - or herself with his or her gender and shapes his future fatherhood. Certain men feel envious about women's procreative ability and unconsciously compete with them by experiencing pregnancy-related symptoms [13].

The literature describes a plethora of predictive factors of the Couvade syndrome. This phenomenon is said to occur more frequently in men who expect the first child $[2,11]$. Kiselica and Scheckel indicate that the youngest fathers are the most susceptible to the development of the Couvade syndrome due to unplanned pregnancy, stress and immaturity to become a father [14]. Bielawska-Batorowicz, however, disagrees and claims that the Couvade syndrome is more common at older age and in men who have close relationships with their mothers [14]. The causes of the Couvade syndrome have not been determined thus far. Professor Klein from the University of Texas classifies the causes into eight categories [15]. Storey et al., based on their own study, described changes in the levels of certain hormones, e.g. an increase in prolactin in men with at least two symptoms of the Couvade syndrome, as well as estradiol and cortisol in response to fear associated with the birth of a child, or a decrease in the level of testosterone, which might be linked with acknowledging a new paternal role [16]. According to the Freudian psychoanalytic theory, one of the causes of the Couvade syndrome is the Oedipus complex, i.e. identification with the mother distorts normal identification with the male role [2]. Brennan et al., on the other hand, advocate idiopathic causes of the Couvade syndrome [7].

\section{OBJECTIVES}

The aim of the study was to assess the occurrence of the symptoms associated with the Couvade syndrome in two groups of men of Polish and Finnish nationality, and to perform a comparative analysis.

\section{MATERIAL AND METHODS}

The survey-based study was conducted in two groups of men (expectant fathers) of Polish and Finnish nationality. The study was performed from March to May 2016 in Poland among the residents of the Silesian Metropolis and in Finland in Satakunta region. The analysis involved 51 Poles and 40 Finns. The groups were comparable in terms of age, education and place of residence.

\section{Study design}

The study was conducted with a self-constructed questionnaire prepared in Polish and English languages. The tested fathers were informed about the purpose and subject of the investigation. The inclusion criteria were: males, a pregnant partner/wife, physiological course of pregnancy and correctly completed questionnaire. The Polish version of the questionnaire was filled in by the users of the "Facebook" service. In Finland, the questionnaire was distributed electronically to a random group of men.

\section{Statistical analysis}

The statistical analysis of the data was performed in Microsoft Office Excel 2010 and Statistica 12. The Pearson's test was calculated, and the level of statistical significance was $p<0.05$.

\section{RESULTS}

\section{Socio-demographic characteristics of the respondents}

The surveyed Poles were 19-40 years old, and the Finnish respondents were aged from 19 to 45 years $(20 \%>40$ years of age). Men aged 19-30 years constituted 53\% and 30\% of the Polish and Finnish respondents, respectively. Higher education was declared by $53 \%$ of the Polish and $50 \%$ of the Finnish men. Eighty per cent of the Poles and $60 \%$ of the Finns were married. More than a half (59\%) of the Polish respondents expected their first child whereas most of the Finns had already had children $(p=0.00010)$ (Fig. 1).

\section{Forms of preparation for childbirth}

The Finnish respondents more frequently than the Polish men used professional forms of preparation for childbirth and parenthood (70\% vs 37\%, $p=0.00229$ ) (Fig. 2). When assessing attendance of men in ante-natal classes during subsequent pregnancies, it was found the number of participants in ante-natal classed decreases with consecutive pregnancies in a statistically significant way $(p<0.05)$ in both groups (Fig. 3). The basic source of information about pregnancy and birth in the group of Polish fathers was the Internet: social media (45\%) as well as guides and books. The Finns drew knowledge about pregnancy and childbirth from medical professionals during meetings with a midwife (70\%) 


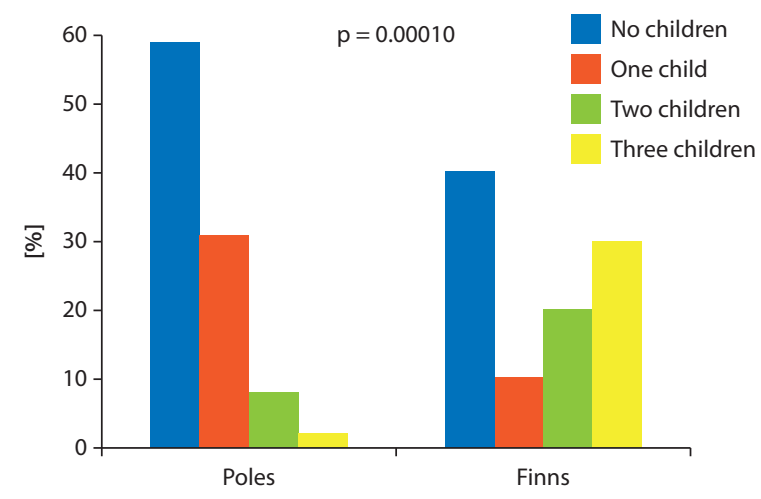

Figure 1. The number of children in the compared groups

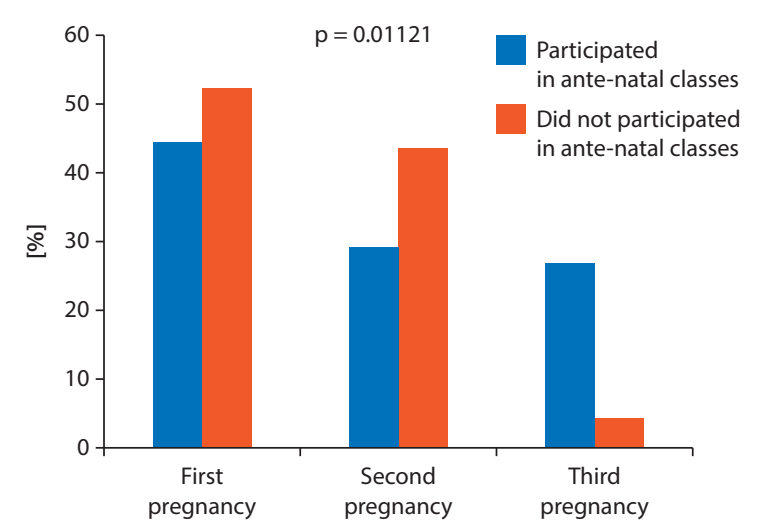

Figure 3. Participation of men in ante-natal classes depending on the number of their partner's pregnancies

Table 1. The prevalence of physical symptoms of the Couvade syndrome in the groups of Poles and Finns

\begin{tabular}{|l|c|c|c|}
\hline $\begin{array}{l}\text { Physical symptoms } \\
\text { of Couvade syndrome }\end{array}$ & Poles & Finns & p-value \\
\hline Weight gain & $78 \%$ & $60 \%$ & 0.0560 \\
\hline Loss of appetite & $2 \%$ & $10 \%$ & 0.0940 \\
\hline Gastric symptoms (heartburn) & $70 \%$ & $10 \%$ & 0.0000 \\
\hline Nausea/vomiting & $10 \%$ & $0 \%$ & 0.0248 \\
\hline
\end{tabular}

Table 2. Emotional symptoms of the Couvade syndrome in the groups of Poles and Finns

\begin{tabular}{|l|c|c|c|}
\hline $\begin{array}{l}\text { Emotional symptoms } \\
\text { of Couvade syndrome }\end{array}$ & Poles & Finns & p-value \\
\hline Mood swings & $60 \%$ & $20 \%$ & 0.0001 \\
\hline Insomnia & $51 \%$ & $10 \%$ & 0.00004 \\
\hline Frustration & $5 \%$ & $20 \%$ & 0.0403 \\
\hline Nervousness & $25 \%$ & $50 \%$ & 0.01579 \\
\hline
\end{tabular}

and though participation in ante-natal classes (20\%). None of the Finnish respondents indicated the Internet as the source of information about pregnancy and labor.

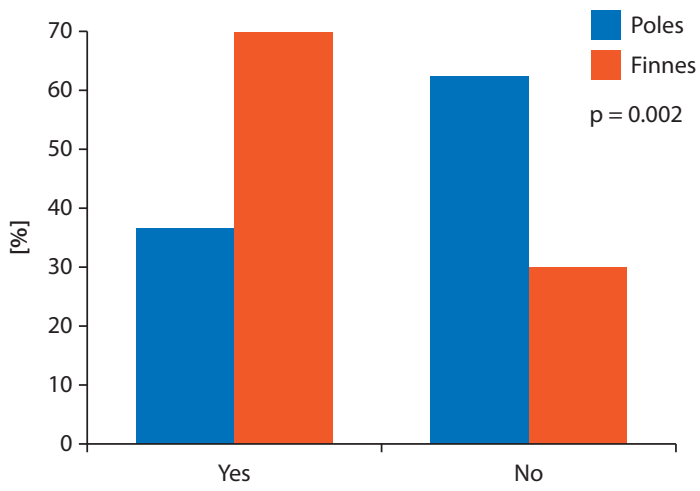

Figure 2. Participation of men in ante-natal classes

Men of both countries were eager to accompany their partners to gynecologist/obstetrician appointments (77\% of the Poles, $80 \%$ of the Finns). Physical and emotional symptoms of the Couvade syndrome are presented in Tables 1 and 2 .

\section{The prevalence of psychosomatic symptoms of the Couvade syndrome}

Both the Polish (78\%) and Finnish expectant fathers (60\%) experienced weight gain when their partners were pregnant. The greatest weight gain was observed in the third trimester. The results were not statistically significant, but the percentages obtained suggest that the body mass increases in men with the progression of pregnancy (consecutive trimesters) (Fig. 4).

The percentage of men experiencing appetite loss in the studied groups was rather low, and it was more common in the Finnish group (10\% vs $2 \%$ ). Most of the Polish expectant fathers (85\%) needed to eat highly calorific products when their partners were pregnant, while the Finnish men reported this symptom in $20 \%$ of cases. Seventy per cent of the Polish fathers experienced heartburn in the period of their partners' pregnancies, whereas the respective values in the

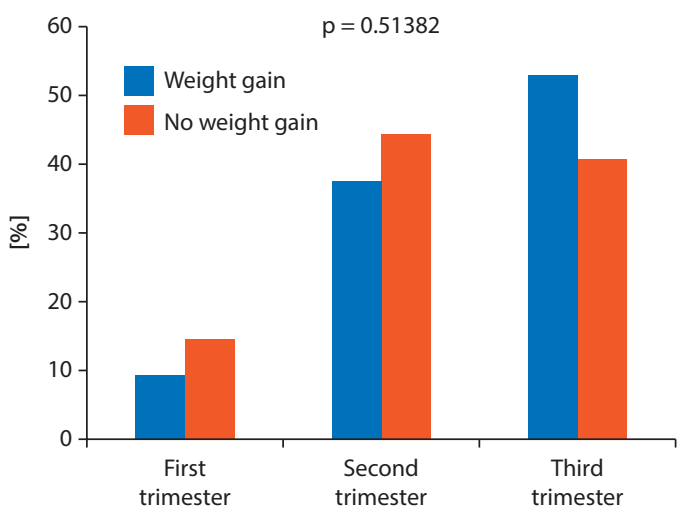

Figure 4. Weight gain in men in consecutive trimesters of pregnancy 
Finns amounted to $10 \%$. The occurrence of nausea/vomiting was declared by $10 \%$ of the Polish respondents. More than a half of the Poles (60\%) experienced anxiety as their wives/partners were pregnant. The Polish fathers more frequently experienced mood swings compared to the Finns $(60 \%$ vs $20 \%, p=0.0001)$. A half of the Finnish respondents, in turn, more frequently declared nervousness $(p=0.01579)$. The Polish fathers more often experienced insomnia (51\% vs $10 \%$ in the Finns, $p=0.00004$ ), whereas the Finns felt frustrated significantly more frequently $(p=0.04032)$.

In the whole group of expectant fathers, the occurrence of two symptoms was the most prevalent (Finns - 98\%, Poles - 43\%). One symptom was found in $12 \%$ of the Poles and $2 \%$ of the Finns. The occurrence of three symptoms was noted only in the Polish population (45\%).

According to the literature reports, the use of stimulants is one of the Couvade syndrome's predisposing factors. The analysis of our data shows that, compared to the Poles, the Finns used more stimulants: $50 \%$ of the Finnish fathers smoked and $100 \%$ drank alcohol. However, when their partners were pregnant, the Finns more frequently stopped using stimulants ( $p=0.00010)$, with significantly higher percentage of men in both Polish and Finnish groups declaring so during the first pregnancy ( $p=0.01129$ ).

\section{Assessment of nutrition, lifestyle and emotions in expectant fathers}

Most of the Polish and Finnish fathers did not change their eating habits as their wives/partners were pregnant, and the percentage values were comparable ( $62 \%$ of Poles and $70 \%$ of Finns). However, $60 \%$ of the Poles and $46 \%$ of the Finns made certain lifestyle changes when their wives/partners were pregnant, with the highest percentage of men (74.19\%) declaring lifestyle changes during the first pregnancy. Subsequent pregnancies were characterized by a significantly lower percentage of men who declared lifestyle changes.

As for the assessment of the men's relationships with their fathers, it was found that both the Finns and Poles usually evaluated their relationships as neutral, $40 \%$ of Finns declared having close relationships with their fathers (5\% of Poles), and $35 \%$ of Poles assessed them as good. Almost all expectant fathers from Poland (99\%) expressed happiness, but at the same time $48 \%$ were anxious about becoming a father and $39 \%$ were worried about the future. Twenty per cent of the Finns declared happiness and euphoria, while $20 \%$ were surprised. They were also anxious about their paternal role (30\%).

\section{DISCUSSION}

Diagnosis of the Couvade syndrome is complex and challenging. There are significant discrepancies between the symptom-based ways to diagnose this condition as presented in the literature. According to Lipkin and Lamb as well as Strickland, the principle of at least one physical symptom should be followed $[5,17]$. Brennan, on the other hand, claims that at least 4 physical or psychological symptoms are needed to establish diagnosis [7]. In Australian studies from 2010, the principle of at least 8 psychological or physical symptoms was followed [10]. As for the Polish research from 2013, the criteria proposed by Lipkin and Lamb were used [18].

In this study, $98 \%$ of the Finnish and $43 \%$ of the Polish expectant fathers experienced two symptoms of the Couvade syndrome. One symptom was found in $12 \%$ of the Poles and $2 \%$ of the Finns. The occurrence of three symptoms was noted only in the Polish population (45\%). According to Brennan [19], contemporary fathers experience psychosomatic symptoms and display typical behaviors during pregnancy, which is confirmed in this study. All men, irrespective of nationality, experienced symptoms of the Couvade syndrome, but the Polish respondents presented both physical and emotional symptoms significantly more frequently. The most common physical symptoms reported by the Polish respondents were weight gain (78\%) and gastric disorders (heartburn 70\%, nausea/vomiting 10\%), whereas the Finns most frequently declared weight gain (60\%). As for emotional symptoms, mood swings $(p=0.0001)$ and sleep disorders $(p=0.00004)$ were significantly more common in the Poles, whilst the Finns experienced frustration $(p=0.0403)$ and nervousness $(p=0.01579)$ significantly more often.

The awareness of parents concerning pregnancy and childbirth has increased in recent years. The possibility to see the gynecologist together for an ultrasound scan and the participation in ante-natal classes strengthen the future father's identification with the unborn child and build bonds between the parents, which might result in the occurrence of symptoms associated with the partner's pregnancy [20]. Both the surveyed Poles (77\%) and Finns (80\%) were eager to accompany their partners to gynecologist/obstetrician appointments.

At present, future fathers experience ambivalent emotions associated with pregnancy. On the one hand, they become co-participants, and on the other, they do not engage in pregnancy, which is perceived as an egoistic attitude to future parenthood and as the lack of empathy. A man who experiences the Couvade syndrome prepares for the new role of a father and for the participation in labor. A professional form of preparation for childbirth and parenthood is ante-natal education. The present study demonstrates that the Finnish fathers more frequently $(p=0.00229)$ took part in professional forms of ante-natal education by accompanying their partners to ante-natal classes. In Poland, merely 
one-third of the couples participated in ante-natal classes, whereas information about pregnancy and childbirth was obtained from the Internet and guidebooks. The lack of professional preparation results in the intensification of both physical and emotional symptoms of the Couvade syndrome in the Polish fathers.

The focused phase of active male participation in pregnancy is observed in the third trimester when men prepare for childbirth and identify themselves with their future role. Certain men feel anxious before childbirth [11, 21]. The results suggest that the body mass increases in men with the progression of pregnancy (consecutive trimesters). The greatest weight gain concerned $53.1 \%$ of the respondents and was observed in the third trimester.

Starowicz et al. showed that lower levels of education predispose to the Couvade syndrome [21]. This relationship was not, however, noticed in this study. The vast majority of the surveyed men, both Poles and Finns, had higher or secondary education.

Brazelton and Cramer, based on their study, concluded that men provide emotional support to their wives/partners throughout pregnancy and labor and accompany them in the course of preparation for childbirth and in caring for the child [9]. This way, they fulfil their role as future fathers. Most surveyed men from both countries accompanied their wives/partners to gynecologist appointments.

Storey et al. describe anxiety associated with the birth of a new family member [16]. Fathers from both countries experienced both negative and positive emotions in a similar way. They declared happiness and euphoria, but also concern about their family's future. Kazmierczak et al. and Kiełbratowska et al. stated that men need the Couvade syndrome to be in the center of the woman's attention and to adjust to the new situation [18, 22]. A contemporary man demands the recognition of his place and role during his wife's/partner's pregnancy and labor. That is why it is justified to continue studies on the modern Couvade syndrome as well as on medical, social and psychological factors that precondition its occurrence.

\section{CONCLUSIONS}

Irrespective of the nationality, contemporary men do experience the Couvade syndrome, which is manifested with one or more psychosomatic symptoms and engagement in care for their pregnant wives/partners. Psychosomatic symptoms of the Couvade syndrome are significantly more common in Polish than in Finnish expectant fathers. Compared with Polish fathers, Finns significantly more frequently attend ante-natal classes. Ante-natal care should encompass education of men as they do experience the symptoms of the Couvade syndrome during their wives'/ /partners' pregnancies.

\section{REFERENCES}

1. Magalini SI. Magalini SC. Dictionary of Medical Syndromes. Lippincott-Raven fourth ed., Philadelphia 1997.

2. Głażewska E. Kuwada. Egzotyczny zwyczaj w nowej odsłonie. Wydawnictwo Uniwersytetu Marii Curie-Skłodowskiej, Lublin 2014.

3. Laplante P. The Couvade Syndrome: The biological, psychological, and social impact of pregnancy on the expectant father. Can Fam Physician. 1991; 37: 1633-1660, indexed in Pubmed: 21228978.

4. Clinton JF. Physical and emotional responses of expectant fathers throughout pregnancy and the early postpartum period. Int J Nurs Stud. 1987; 24(1): 59-68, indexed in Pubmed: 3644801.

5. Lipkin M, Lamb GS. The couvade syndrome: an epidemiologic study. Ann Intern Med. 1982; 96(4): 509-511, indexed in Pubmed: 7199885.

6. Conner GK, Denson V. Expectant fathers'response to pregnancy: review of literature and implications for research in high-risk pregnancy. J Perinat Neonatal Nurs. 1990; 4(2): 33-42, indexed in Pubmed: 2391646.

7. Brennan A, Marshall-Lucette $S$, Ayers $S$, et al. A qualitative exploration of the Couvade syndrome in expectant fathers. Journal of Reproductive and Infant Psychology. 2007; 25(1): 18-39, doi: 10.1080/02646830601117142.

8. Bancroft J. Seksualność człowieka. Elsevier Urban \& Partner, Wrocław 2011.

9. Brazelton TB, Cramer B. The earliest relationship: parents, infants, and the drama of early attachment. Perseus Books., Cambridge 1990.

10. Brennan A. Couvade Syndrome in Australian Men: A National Survey. 2010. http://www.abc.net.au/catalyst/fatherhood/CatalystCouvadeSurveyAustralia. (28.05.2016).

11. Bielawska-Batorowicz E. Psychologiczne aspekty prokreacji. Wydawnictwo Śląsk, Katowice 2006.

12. Radhakrishnan R, Satheeshkumar G, Chaturvedi SK. Recurrent delusions of pregnancy in a male. Psychopathology. 1999; 32(1): 1-4, indexed in Pubmed: 9885393.

13. Miller GP, Custody and Couvade: The importance of paternal; bonding in the law of family relations. Indiana Law Review 2000;33,3:691-736. http://mckinneylaw.iu.edu/ILR/pdf/vol33p691. (28.04.2016).

14. Kiselica MS, Scheckel S. The Couvade Syndrome (sympathetic pregnancy) and teenage fathers: A brief primer for school counsellors. School Counsellor. 1995; 43(1): 42-52.

15. Mason C, Elwood R. Is there a physiological basis for the couvade and onset of paternal care? Int J Nurs Stud. 1995; 32(2): 137-148, indexed in Pubmed: 7790154.

16. Hormonal correlates of paternal responsiveness in new and expectant fathers. Evol Hum Behav. 2000; 21(2): 79-95, indexed in Pubmed: 10785345.

17. Strickland OL. The occurrence of symptoms in expectant fathers. Nurs Res. 1987; 36(3): 184-189, indexed in Pubmed: 3646620.

18. Kazmierczak M, Kielbratowska B, Pastwa-Wojciechowska B. Couvade syndrome among Polish expectant fathers. Med Sci Monit. 2013; 19: 132-138, doi: 10.12659/MSM.883791, indexed in Pubmed: 23425940.

19. Brennan A, Ayers $\mathrm{S}$, Ahmed $\mathrm{H}$, et al. A critical review of the Couvade syndrome: the pregnant male. Journal of Reproductive and Infant Psychology. 2007; 25(3): 173-189, doi: 10.1080/02646830701467207.

20. Syty K, Pilewska-Kozak AB, Jakiel G. Reakcje kobiet i ich partnerów na fakt zaistnienia ciąży. Perinatol Neonatol Ginekol. 2008; 3(1): 217-221.

21. Lew-Starowicz Z, Cyranek J, Szymańska M. Zespół kuwady. Przegląd Seksuologiczny, styczeń/marzec 2011; 25. http://przeglad-seksuologiczny. pl/numery/25/PS_NR_25_ART_1. (28.04.2016).

22. Kiełbratowska B, Kazmierczak M, Michałek J, et al. Couvade syndrome perceived by medical Staff and partners of expectant fathers. Gin Pol Med Project. 2015; 3(37): 42-48. 